Polyanska Alla, Doctor of Economics, Professor, Ivano-Frankivsk National Technical University of Oil and Gas (Ivano-Frankivsk, Ukraine)

Shyroka Khrystyna, Bachelor of Management, Ivano-Frankivsk National Technical University of Oil and Gas (Ivano-Frankivsk, Ukraine)

\title{
RESOURCE APPROACH TO MANAGEMENT ENTERPRISES IN THE CONDITIONS OF KNOWLEDGE ECONOMY
}

\begin{abstract}
The article investigates a resource approach in the management of the enterprise, which focuses on those types of resources that enable the company to advance its development in accordance with current trends of development. The tendencies of innovation development of enterprises based on the construction of the econometric model of the distributed lag are investigated. It is determined that the defining condition for improvement of innovation development is the application of modern management concepts based on the principles of knowledge and digital economy. The essence of resource provision of knowledge and digital economy is determined. The advantages that companies will receive in case of optimization of the resource structure using knowledge and digital economy tools are described.
\end{abstract}

Keywords: resources, enterprise, potential, management, knowledge economy, digital economy

\section{Formulation of the problem}

The priorities that advance modern development of both the economy of individual countries and individual enterprises are formed in the condition of knowledge economy. It is based on the use of such specific factors of production as information, knowledge, intellectual product, communication system in contrast of labor, technical, and financial factors that were characteristic of the industrial type of social development.

The concept of production increasing as a result of the quantitative growth of all its factors on the base of unchanged qualitative level of production technical basis and other factors in the conditions of limiting production resources as well as the need to increase the level of competitiveness, changes to the concept of intensification of economic processes. This new approach is accompanied by an increase in the returns of the resources used and production efficiency. Intensive development involves the growth of labor productivity and efficiency on the basis of enterprise resources optimal structure, rational use of them, and requires the study of a resource management approach with usage of savings and computer means and skilled labor, 
advanced forms and methods of work organization, growing awareness of the latest advances in scientific and technological progress.

\section{Analysis of recent research and publications}

The question of resources efficient management maximizing is constantly under attention of scientists. Among foreign scientists it is worthwhile to distinguish Vernhelfelt B. [1], who was one of the first developed the concept of the resource approach, as well as Barney D. [2], who introduced in his work the basic notions on which the resource approach is based, Collis D. and Mantgemeri S.A. [3], the work of which is highlighted in the work "Resource Competition", Kleiner G. [4] and others.

Investigating the structure of resource provision of individual enterprises, scholars consider different approaches to its evaluation and achievement of efficiency growth. In particular, O. Skalenko notes that "the principles of social and economic growth... are naturally based on three bases, namely information, intellectual and innovation" [5, p. 176]. V. Vasilenko stresses that the basis of the enterprise's operating should lie on its potential, defined as "sources, opportunities, means, stocks that can be used to solve any tasks, to achieve a certain goal, the ability of individual, as well as particular industry, society, state " [6, p. 83]. O. Balatsky under the economic potential considers the aggregate capacity of available economic resources to ensure the production of the maximum possible volume of utility that meets the needs of society at this stage of its development. The value of economic potential is determined by the number and quality of economic resources that are available and can be involved in public production, as well as by the conditions for their most effective use [7, p. 140]. B. Carlof emphasizes the management of resources to achieve internal efficiency, and under the resources understands the combination of costs and capital [8, p. 152]. Particular attention in today's foreign economic literature is devoted to the development of human resources that are part of the intellectual potential and are considered as an important factor in organizational development. The development of human resources "provides the mobilization of reserves for the growth of operational efficiency, eliminates all kinds of obstacles in this way and motivates staff" [9, p. 97]. The development of human resources is associated with the need to implement the concepts of "self-learning organizations". Peter Senge described the theory and practice of "self-learning organizations" from the point of view of "five disciplines", which includes many tools and infrastructures, namely: 1) system thinking; 2) improvement of personality; 3) intellectual models; 4) general vision; 5) group learning [10]. 
Hence, it is now important to determine the optimal structure of resources that ensure the effective operation of the enterprise and greatly facilitate the search of the main ways to improve the utilization of resource potential in a context of growing competition not only at the country level but also within the international community. The resources which are available at the enterprise, their quantity and quality are a significant factor of current situation [11, p. 132], and measures concerning the fulfillment of necessary changes should be made taking into account the following situational characteristics: the availability of resources without which it is impossible to maintain the parameters of viability and changes making; comparison of resources available in the organization with those that are needed to implement the plans; elucidation of a realistic picture of the potentialities of business entities; ensuring the possibility of plans implementing through more efficient use of available resources and the creation or attraction of new ones. Martynenko V. pointed out the technology that is the factor having the greatest impact on productivity, but in interaction with another factor - staff [12, p. 21]. J. Schumpeter noted that the new combination, which may arise as a result of the combination of available materials and the power that occurs in discrete conditions, characterizes enterprise's development [13]. The resource structure can also take part in creation of this combination. So, it is important to determine how to combine and use existing potential that is based on the resources, to achieve development goals in the best way.

\section{Selection of previously unsettled parts of the general problem}

Despite the number of publications, this issue remains relevant, since changing of the development priorities shifts the emphasis on researching the types of resources that are drivers for changes.

The purpose of the article is to justify the resource approach in the management of the organization with allocation of the structure of resources that correspond to the latest knowledge-based development trends.

\section{Research methodology}

Enterprise management is accompanied by the need to adjust the structural balance of enterprise resources to maintain its viability. Proceeding from the fact that resources are the main component of the organization's development potential, it is necessary to determine its resource structure, through which it would be possible to react flexibly to changes and adapt to them the economic activity (Fig. 1). 


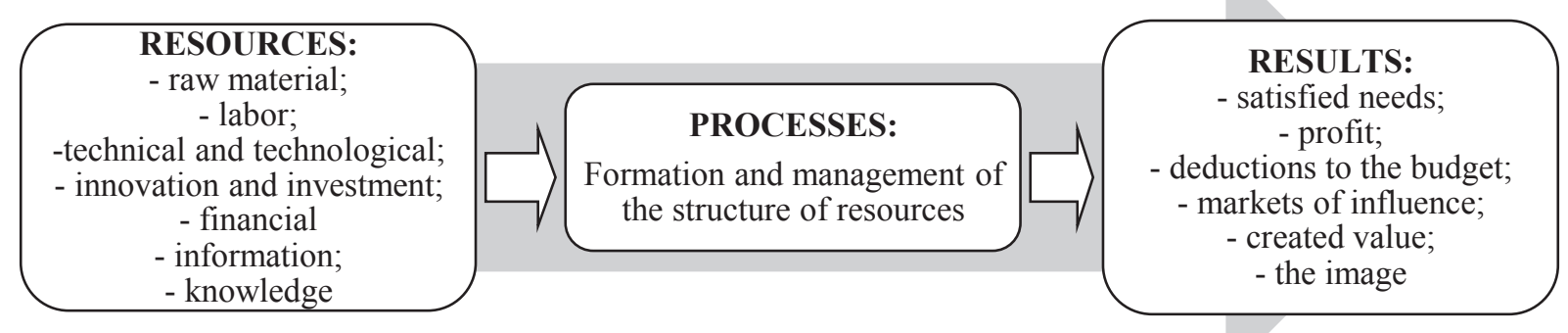

Fig. 1. The process of transformation of resources into the results of the enterprise

Sources: formed by the author

The resource structure for each enterprise is individual, based on the specifics of the industry in which it operates, the level of economic development, potential opportunities, the chosen development strategy. Management of the resource component of the enterprise involves a continuous process of optimizing the use and replacement of resource elements.

It should be noted that for many economic processes, the typical fact is that the effect of the impact of the resource on the result is not immediately, but gradually, after a certain period of time. This phenomenon is called a lag (delayed), and the value of $\tau$ is called a shift. The shift, which corresponds to the highest correlation coefficient, is called time delay or time lag. Measurement of the relationship between economic indicators that characterize a particular type of resource, taking into account the lag, is carried out on the basis of constructing of the econometric model of a distributed lag [14, 15, p. 217]:

$$
y_{t}=\sum_{j=0}^{\infty} a_{j} x_{t-\tau}+u_{t}
$$

The coefficients ${ }^{a_{j}}, \mathrm{j}=0,1,2,3 \ldots$, are called the lag coefficients, and the sequence $\mathrm{a}=\left\{{ }^{a_{j}}, \mathrm{j}=0,1,2,3 \ldots\right\}$ is the structure of the lag; $x_{i-r}$ - explanatory lag variable; $\mathrm{t}$ - time; $\mathrm{r}$-period of shift (time lag); $u_{t}$ - the remainders, which are distributed according to the normal law, that is, have zero mathematical expectation and constant dispersion.

If the econometric model includes not only lag variables, but also variables characterizing the current conditions of the functioning of economic systems in which resources are used, then such a model is called the generalized model of a distributed lag and is written in the form:

$$
y_{t}=\sum_{\tau \geq 0} a_{\tau} x_{t-\tau}+\sum_{s=1}^{m} b_{s} z_{t, s}+u_{t}
$$

$z_{t, s}$ - explanatory variables of current conditions; ${ }^{b_{s}}$ - the coefficients of these explanatory variables. 
Since the parameters a $a_{\tau}$ relate to the same lag variable that affects the dependent variable for a certain time, then $w=\sum_{\tau} a_{\tau}=1$ expresses the total effect of this lag variable on the dependent, where $w$ is a finite number. To justify the lag or lags it is expedient to use a mutual correlation function. This function characterizes the closeness of each element connection of the vector of a dependent variable $y_{t}$ with an element of an independent vector $x_{t}$ shifted relative by one relatively to other in the time lag $\tau$.

$$
r_{(\tau)}=\frac{(n-\tau) \sum_{t=1}^{n-\tau} y_{t} x_{t+\tau}-\sum_{t=1}^{n-\tau} y_{t} \sum_{t=1}^{n-\tau} x_{t+\tau}}{\sqrt{\left[(n-\tau) \sum_{t=1}^{n-\tau} y_{t}^{2}-\left(\sum_{t=1}^{n-\tau} y_{t}\right)^{2}\right]\left[(n-\tau) \sum_{t=1}^{n-\tau} x_{t+\tau}^{2}-\left(\sum_{t=1}^{n-\tau} x_{t+\tau}\right)^{2}\right]}}
$$

For different values $\tau$ on the basis of the mutual correlation function it can be obtained the $\mathrm{n}+1$ value $r_{(\tau)}$. If $\tau=0$, we have a pairwise correlation coefficient. Values $r_{(\tau)}$ are

contained in the plural $\left.r_{(\tau)} \in\right]-1,1\left[\right.$. The largest value $r_{(\tau)}$ by module (closest to one) determines the shift, or time lag. If there are several values $r_{(\tau)}$ in a set of values that are closer to one, then this means that the late effect of the variable $x_{t}$ occurs over a certain period of time, and as a result, we have several time lags for the two interrelated time series. Finding time lags to determine the relationship between economic indicators of resource usage, it is possible to build an econometric model of a distributed lag.

\section{Research results}

Resource potential of each enterprise is characterized by the structure of necessary and accessible resources depending on the branch affiliation, nature of production, location; a decision-making system for the formation and implementation of resource strategies, depending on the forms of ownership and the level of management of the enterprise; optimal resource ratio for achieving development goals.

The significance and impact of resources on the enterprise's efficiency is determined by the resource's role to achieve the objectives of the enterprise, the possibilities of its replacement, the level of prices influence on resource's structure and is evaluated by a system of indicators that characterize the efficiency of utilizing enterprise resources and their impact on the final results of the activity. Thus, the efficiency of the use of raw material resources can be determined through indicators of material content, depth of processing of raw materials, fractions of waste. The assessment of labor resources efficiency is carried out by using of labor productivity indicators, profits per employee, the share of growth in turnover through increased productivity. 
Indicators of the efficiency of the financial resources use can be profit, profitability, and share of equity capital, liquidity, and solvency. The efficiency of technical and technological resources use can be calculated by using indicators of capital stock, return on assets, and level of capacity utilization, capital intensity, and capital efficiency. The efficiency of energy resources use requires the definition of energy intensity, energy supply, level of losses. To determine the efficiency of innovative resources using can be by means of indicators of the proportion of new products and procecces in organization, the number of registered patents, the average term of the patents of the enterprise, the number of rationalization proposals per employee. To determine the effectiveness of information resources using, you can use indicators such as the level of information support activities of the organization, the level of information updates as well as the level of access of employees to information that directly affects their activities.

It should be noted that the prospects for implementation of the specified measures for enterprises development to a large extent depend on how situations that hinder the process can be complex and systemic resolved. Taking into account the sectoral structure imperfection of the domestic industry, the suboptimal use of its production, investment, scientific and technological potential, the possibility of improving the situation in the short term is unlikely. However, consolidating the institutional, organizational and economic basis for economic reform can provide additional impulse to the development of the industrial sector. The abovenoted can be confirmed with the help of the correlation coefficient (formula 3). Based on the data of Tab. 1 we carry out its calculation to determine the impact of innovation factors on the volume of gross product created in the industrial sector.

Table 1. Output data to calculate the correlation coefficient

\begin{tabular}{|c|c|c|c|c|}
\hline Period & $\begin{array}{c}\text { GDP in industrial } \\
\text { production, thousand UAH } \\
y_{t}\end{array}$ & $\begin{array}{c}\text { The rate of growth } \\
\text { of capital investment } \\
\mathrm{x}_{l}\end{array}$ & $\begin{array}{c}\text { Introduced new techno- } \\
\text { logical processes } \\
\text { in industry, units } \mathrm{x}_{2}\end{array}$ & $\begin{array}{c}\text { Mastered the types } \\
\text { of innovative products } \\
\text { in industry, units, } \mathrm{x}_{3}\end{array}$ \\
\hline 2002 & 243914 & 108,9 & 1482 & 8416 \\
\hline 2003 & 292133 & 131,3 & 1142 & 22847 \\
\hline 2004 & 389547 & 128 & 1727 & 3978 \\
\hline 2005 & 476927 & 101,9 & 1808 & 3152 \\
\hline 2006 & 550172 & 119 & 1145 & 2408 \\
\hline 2007 & 706664 & 129,8 & 1647 & 2446 \\
\hline 2008 & 920854 & 97,4 & 1893 & 2685 \\
\hline 2009 & 792473 & 58,5 & 2043 & 2408 \\
\hline 2010 & 1033189 & 99,4 & $\ldots$ & $\ldots$ \\
\hline$\ldots$ & $\ldots$ & $\ldots$ & 3489 & 2387 \\
\hline 2017 & 1970207 & 123,4 & & 263 \\
\hline
\end{tabular}

Sources: the data of ukr.stat.gov [16] 
Data of Tab. 1 demonstrate the dynamic of indicators which characterized the innovation development of country and the gross product created in the industrial sector which is the criteria of state welfare. Determination of the relationship between economic indicators $\left(x_{i}\right)$ and result indicator $(y)$ on the base of econometric model of a distributed lag 3 will show when mentioned indicatos affect the total result of state economic development (the value of $r_{(\tau)}$ tend to 1 ). Thus, the calculations made it possible to establish that the influence of innovation factors on industrial development can be characterized as follows:

1) the return on capital investment in industrial development can be expected in 3-5 years (Fig. 2);

2) the results from the introduction of new technological processes in industry are likely in the near future (Fig. 3);

3) the result from the development of new types of innovative products should be expected on the 2nd-3rd year (Fig. 4).

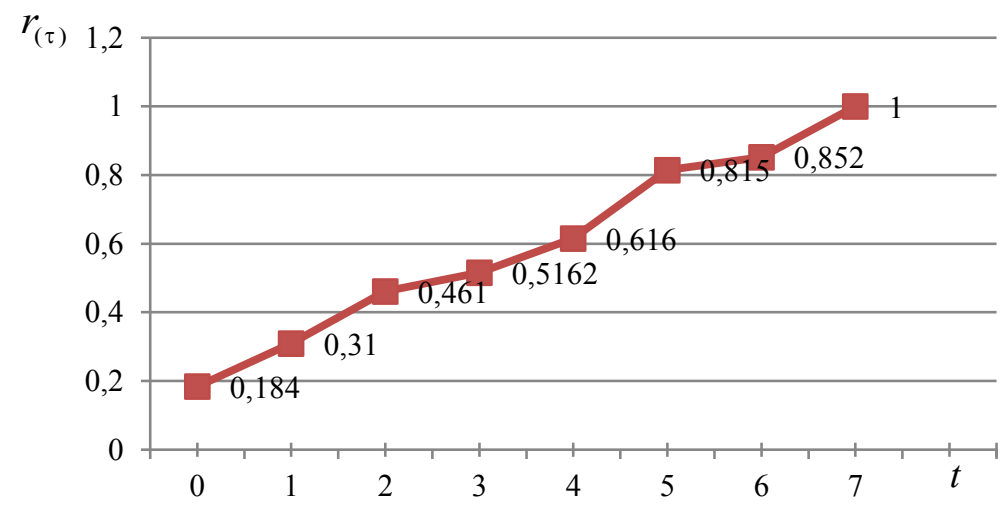

Fig. 2. Correlogram of mutual correlation function, characterizing the density of connection between the rate of growth of capital investment and GDP volumes in industry [17]

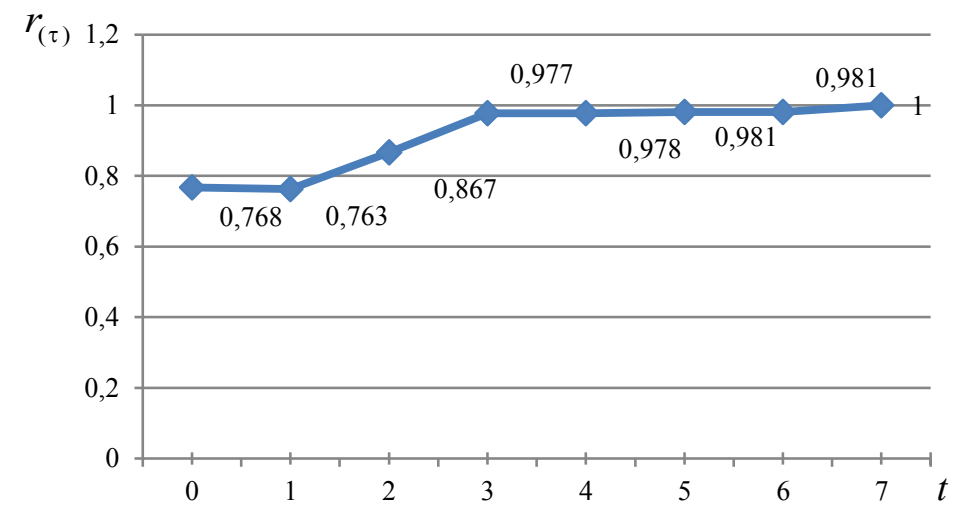

Fig. 3. Correlogram of mutual correlation function characterizing the density of connection between introduction of new technological processes in industry and volumes of GDP in industry [17] 


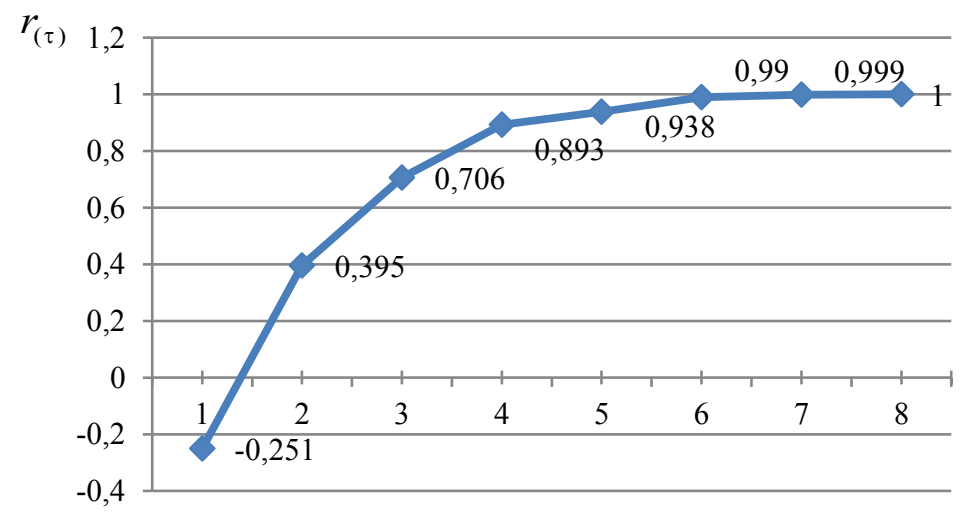

Fig. 4. Correllogram of mutual correlation function, characterizing the density of connection between the development of types of innovative products in industry and volumes of GDP in industry [17]

So, the results of calculation are presented on figures 2-4 that demonstrate that the time lag of innovation resources influence on the development has in avarrage 3 years that is very unfavorable in the conditions of modern challenges. Researches conducted by scientists on the issues of domestic innovation development allow us to agree with the conclusion that under the existing conditions of innovation activities financing and the peculiarities of the development of the industrial sector with the remains characteristics of post-Soviet management, the duration of the investment cycle is quite significant and covers up to six years, which is unacceptable in an innovative economy [14, p. 357]. To our opinion, the solution of the abovementioned issues is connected with the achievements in the sphere of knowledge management. Because knowledge management is the process of creating, sharing, using and managing the knowledge and information of an organisation [18], and knowledge is a source of creation of ways to improve business performance [19] including resources usage.

Modern realities are formed on the gradual growth of knowledge importance, and as a consequence, the transition to a knowledge economy. An important direction for the development of domestic companies is to increase of the part of the intellectual results of labor relative to the material. Endeed, it is thanks to the results of the effective implementation and application of the basic principles of a knowledge economy it is possible to introduce innovations into the material activities. The concept of knowledge economy brings new requirements to resource support. Consequently, the traditional resource structure is expanding with a new element. F. Mahlup [20] defines the subject of knowledge economics not only as an analysis of the information sector, the production of new knowledge, the mechanism of acquiring and transferring skills and abilities, but also the study of theoretical problems of choice and decision making under conditions of uncertainty and incomplete information. In the narrow sense, 
the knowledge economy concentrates exclusively on the production, acquisition, distribution of knowledge, as well as competencies and abilities to study.

The potential of implementing the knowledge economy elements into the system of economic relations is based on four main areas of economic development: the education system, information and telecommunication infrastructure, an efficient system of innovations and institutional regime. These trends are estimated within the Knowledge Economy Index (KEI) proposed by specialists of the World Bank. KEI is a conditional indicator on which ground the level of knowledge economy in any country can be established, as well as the tendency of such an economy to develop. The method of calculating the KEI index is based on the assessment of 148 parameters across 146 countries, while for each of the above-mentioned directions individual intermediate indices are calculated [21].

World Bank researchers found that a higher level of the KEI index indicates a potentially higher rate of economic development (with equal conditions). Thus, an increase in the value of the KEI index by one point is equivalent to an increase in the country's rating by 13 points or an increase of $0.46 \%$ in economic development [22].

By studying the various signs of the knowledge economy, identified by scientists, it is worth to highlight some features characteristic of the economy of knowledge. First, in the economy of a country in which the level of knowledge economy increases the percentage of service provision relative to production increases, as a result. Secondly, information, knowledge, and innovative resources become one of the most important and most demanded in the context of the development of the knowledge economy. Thirdly, the cost of searching for and analyzing information, advertising, market research, etc. is increasing. Fourth, thanks to scientific achievements, new forms of economic practice, such as e-commerce, the use of electronic funds, etc., are being developed and are developing [23]. These features should be taken into account by enterprises in shaping and optimizing their resource structure. We should as well draw attention to the important direction of of the knowledge economy development - the digital economy, based on digital computer technologies that improve communication processes and facilitate the process of controlling the target use of resources, ensuring the integrity and transparency of management [24, 25]. Based on the annually results of the World Forum in Davos, the digital economy is seen as a global platform for cooperation to build a digital economy that is sustainable, inclusive and trustworthy [26].

Taking into account the above mentioned peculiarities of resource management in the conditions of knowledge economy and the results of our investigations in the field of inno- 
vative development, we distinguish the following directions of improvement of the company's activity on the basis of resource management improving, namely: reducing the cost of resource provision of the enterprise by monitoring its rational and targeted use; avoiding unnecessary (economically inappropriate) activities that require additional resources; creating competitive advantages based on the search and selection of a resource structure that will create unique value added [27].

\section{Conclusions}

Summarizing the abovenoted, it should be emphasized that the necessary condition for the advance development of the enterprise is the choice of optimal structure of resource to support the effective work in conditions of dynamic changes. Using of optimal resources structure and its priorities will allow providing the forward looking enterprises development. At the same time, the necessary condition for efficient resource management is their intensive use, based on the introduction of advanced scientific and technological progress, the application of new technologies, the improvement of the level of education and skills of emploees, the improvement of forms and methods of production organization, the economical expense of human, financial and natural resources, etc.

The achievement of development goals in such conditions allows enterprises to create a new quality on the basis of the principles of a resource approach aimed at achieving the key principles of the knowledge economy. It is about the creating of economic incentives to promote and effectively use national and global knowledge in all sectors of the economy; the formation of an effective innovation system that unites business, science on the base of research centers, universities or other institutions and power; qualitative transformations in education with the possibility of obtaining for all high-quality and continuous education (lifelong learning); the development of a dynamic information infrastructure and a competitive information sector that provides communication services and accessible information to all sections of society; usage the digital technologies to provide transparency, control and target utilysing of all kinds of resources. 


\section{References}

1. Wernerfelt B. (1984). Resource Based View of the Firm. Strategic Management Journal, 5, 2. https://doi.org/10.1002/smj.4250050207

2. Barney J. (1991). Firm Resources and Sustained Competitive Advantage. Journal of Management, 17 (1). https://doi.org/10.1177/014920639101700108

3. Collis D. J., Montgomery C. A. (2008). Competing in Resource. Harvard Business Review, July-August.

4. Makarov V., Kleiner G. (2007). Microeconomics of Knowledge, 204 p.

5. Skalenko O. (2000). Global Reserves of Progress, 394 p.

6. Vasilenko V. (2005). Management of Sustainable Development of Enterprises, 648 p.

7. Balatsky O. (2006). Economic potential of administrative and production systems. Sumy: IUD "University Book", 973 p.

8. Carloff B. (1991). Business Strategy, 239 p.

9. D. Joy-Matthews, D. Megginson, M. Surt. (2006). Development of human resources, $429 \mathrm{p}$.

10. Senge Peter M. (1999). Fifth Discipline: The Art and Practice of a Self-Learned Organization, $408 \mathrm{p}$.

11. Waters D. (2003). Logistics. Supply Chain Management, 503 p.

12. Martynenko V. (2006). Viability Strategy for Industrial Enterprises, 328 p.

13. Joseph A. Schumpeter. (2011). The Theory of Economic Development: An Inquiry into Profits, Capital, Credit, Interest and the Business Cycle, 242 p.

14. Maslak O., Bone O. (2010). Diversification of innovation development of industry in Ukraine, $456 \mathrm{pp}$.

15. Nakonechny S., Tereshchenko T., Romanyuk T. (2000). Econometrics, 296 p.

16. Polyanska A.C. (2012). Development of industrial enterprises on the basis of situational management: theory and methodology. Thesis for the degree of Doctor of Economics. Ivano-Frankivsk.

17. Ukraine in figures 2017. Statistical Yearbook. State Statistics Service of Ukraine. Available online at: http://www.ukrstat.gov.ua/

18. Girard, John P.; Girard, JoAnn L. (2015). Defining knowledge management: Toward an applied compendium". Online Journal of Applied Knowledge Management, 3 (1): 14.

19. Gaby Neumann, Eduardo Tomé. (2007). The Changing Role of Knowledge in Companies: How to Improve Business Performance through Knowledge. Available online at: https://www.unc.edu.

20. Machlup, Fritz. (1966). The Production and Distribution of Knowledge in the United States, $462 \mathrm{p}$. 
21. Soumitra Dutta, Bruno Lanvin, and Sacha Wunsch-Vincent. Global innovation index 2018 Energizing the World with Innovation.

Available online at: https://www. globalinnovationindex.org

22. Forey D. (2004). Economics of Knowledge. L.: The MIT Press, p. 2 https://doi.org/10.7551/mitpress/2613.001.0001

23. Chukhno A., Leonenko P., Juhymenko P. (2010). Institutional-informational economy, $687 \mathrm{p}$.

24. Koljadenko S. (2016). Digital Economy: Preconditions and Stage of Attitude in Ukraine and the World . Economics. Finances. Management: topical issues of science and practice, 6, 105-112. Available online at:http://nbuv.gov.ua

25. Tapscott Don. (1999). Electronic-digital society: Pros and cons of the era of network intelligence. Kyiv: ITN Press; M.: Refl-Beech, 403 p.

26. Shaping the Future of Digital Economy and Society Available online at: https://www. weforum.org/system-initiatives/shaping-the-future-of-digital-economy-and-society

27. Musina L. (2003). Basic Principles of the Transition to the Knowledge Economy: Perspectives for Ukraine. Economy and Forecasting, 3, 87-108. 